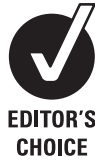

${ }^{1}$ UCL Centre for Altitude, Space and Extreme Environment Medicine, Institute of Human Health and Performance, University College London, London, UK; ${ }^{2}$ Department of Anesthesia and Critical Care, Massachusetts General Hospital, Boston, Massachusetts, USA;

${ }^{3}$ University of Utah, College of Nursing and School of Medicine, Salt Lake City, Utah, USA

Correspondence to:

Dr J S Windsor, UCL Centre for Altitude, Space and Extreme

Environment Medicine, Institute of Human Health and Performance, University College London, Charterhouse Building, Archway Campus, Highgate Hill, London N19 5LW, UK;

jswindsor@doctors.org.uk

Received 9 January 2009 Accepted 6 February 2009

\title{
Mountain mortality: a review of deaths that occur during recreational activities in the mountains
}

\author{
J S Windsor, ${ }^{1}$ P G Firth, ${ }^{2}$ M P Grocott, ${ }^{1}$ G W Rodway, ${ }^{1,3}$ H E Montgomery ${ }^{1}$
}

\section{ABSTRACT}

The growing popularity of activities such as hiking, climbing, skiing and snowboarding has ensured that the number of visitors to mountain environments continues to increase. Since such areas place enormous physical demands on individuals, it is inevitable that deaths will occur. Differences in the activities, conditions and methods of calculation make meaningful mortality rates difficult to obtain. However, it is clear that the mortality rate for some mountain activities is comparable to hang gliding, parachuting, boxing and other pastimes that are traditionally viewed as dangerous. Deaths in the mountains are most commonly due to trauma, high altitude illness, cold injury, avalanche burial and sudden cardiac death. This review describes the mortality rates of those who undertake recreational activities in the mountains and examines the aetiology that lies behind them.

The highest of mountains is capable of severity, a severity so awful and so fatal that the wiser sorts of men do well to think and tremble even on the threshold of their high endeavour-George $L$ Mallory

Mountainous regions occupy 40 million $\mathrm{km}^{2}$ and account for approximately $27 \%$ of the Earth's surface. ${ }^{2}$ It is estimated that 38 million people live permanently above 8000 feet $(2439 \mathrm{~m})$, with an additional 100 million visitors travelling to mountain regions for work and recreation each year. ${ }^{34}$ The increasing popularity of activities such as trekking and climbing has ensured that these numbers continue to grow. The number of trekkers in Nepal has risen by 330\% from 1982 to 1994, and by $450 \%$ from 1994 to $2000 .^{5}$ A similar increase has also been seen at above $6000 \mathrm{~m}$ : in the 40 years between 1950 and 1990, 19810 climbers attempted the highest peaks in Nepal compared with 30141 between 1990 and $2006 .{ }^{6}$

Mountains are inherently dangerous. The combination of falling barometric pressure, temperature and humidity, together with increases in solar radiation and wind speed, mean that those heading to the mountains often encounter an extraordinary set of physical challenges. ' Clearly, managing these challenges can prove enormously satisfying, however in some cases these factors can contribute to serious injury or even death. This review identifies the mortality rates of those who undertake recreational activities in the mountains and examines the aetiology that lies behind them.

\section{CALCULATING THE MORTALITY RATE IN A MOUNTAINOUS ENVIRONMENT}

Obtaining a meaningful and accurate picture of mortality in the mountains is not a straightforward task. While the number of deaths for any given activity provides a basic level of factual information, this does little to identify the degree of risk that an individual is exposed to. Although 58 more deaths were attributed to swimming than mountaineering in England and Wales between 1982 and 1988, this does not necessarily imply that swimming is more dangerous. ${ }^{8}$ Instead it may simply reflect the fact that more individuals participate in swimming than mountaineering activities. In a similar way, the increase seen in mountaineering fatalities in the USA over the last 50 years does not necessarily suggest that mountaineering has become more hazardous, but may instead reflect the growing number of participants. ${ }^{9}$

In order to determine the mortality rate of different mountain activities, researchers have adopted two methods of calculation, and these are described below.

\section{The number of deaths divided by the total number of individuals exposed}

In 1988, Pollard and Clarke published a short report in the Lancet that identified 23 fatalities that had occurred on 83 expeditions to mountains above $7000 \mathrm{~m}^{10}$ Since these expeditions had $533 \mathrm{mem}$ bers, a mortality rate of 4.3 per 100 mountaineers was cited. However, since many of these expeditions were focused upon dangerous and technically challenging objectives like $\mathrm{K} 2$, this rate was somewhat higher than that found in subsequent studies. For many years the historian Elizabeth Hawley and her colleagues in Kathmandu have diligently assembled a comprehensive database containing information on the vast majority of mountaineering expeditions undertaken in the Nepali Himalaya. ${ }^{6}$ Between 1990 and 2006, Hawley and her colleague Richard Salisbury identified mortality rates of between 0 and 1.26 deaths for every 100 mountaineers climbing above $6000 \mathrm{~m}$ (table 1).

On Mt Everest the mortality rate among those who ascend above base camp is $1.3 \%$, with the majority of deaths (82.3\%) occurring during or following the day of a summit attempt. ${ }^{11}$ The mortality rate among trekkers in Nepal is significantly lower. Between 1984 and 1987 only 23 deaths were reported. Since approximately 148000 individuals were issued with trekking permits from the Nepali Ministry of Tourism, the mortality rates during two periods between 1984 and 1991 have been calculated as 0.014 and 0.015 per 100 
Table 1 The mortality rate for mountaineers climbing above $6000 \mathrm{~m}$ in the Nepali Himalaya between 1990 and $2006^{4}$

\begin{tabular}{lccl}
\hline $\begin{array}{l}\text { Peak altitude } \\
\text { range }\end{array}$ & $\begin{array}{l}\text { Individuals above } \\
\text { base camp }\end{array}$ & $\begin{array}{l}\text { Deaths above } \\
\text { base camp }\end{array}$ & $\begin{array}{l}\text { Mortality rate } \\
\text { (/100 individuals above } \\
\text { base camp) }\end{array}$ \\
\hline $6000-6499$ & 712 & 0 & 0 \\
$6500-6999$ & 4509 & 34 & 0.75 \\
$7000-7499$ & 3814 & 48 & 1.26 \\
$7500-7999$ & 961 & 11 & 1.14 \\
$8000-8499$ & 9365 & 116 & 1.23 \\
$8500-8850$ & 10780 & 122 & 1.11 \\
Total & 30141 & 331 & 1.10 \\
\hline
\end{tabular}

The mortality rate is calculated by dividing the number of deaths by the total number of individuals who have climbed above a designated base camp and multiplying by 100 .

trekkers. ${ }^{12}{ }^{13}$ Mountaineering mortality rates in North America lie between these figures. On Denali, the highest mountain in Alaska, 0.308 deaths have been reported for every 100 mountaineers who register with the National Park Service. ${ }^{14}$ Meanwhile on Mt Rainier, a popular $4392 \mathrm{~m}$ peak in the north west state of Washington, 50 deaths were reported between 1977 and 1997. ${ }^{15}$ Since approximately 8000 attempts are made on this mountain each year, an estimated mortality rate of approximately 0.031 per 100 mountaineers can be calculated.

In recent years the mortality rate calculated in this way has appeared to decline. According to Hawley and Salisbury, the mortality rate between 1950 and 1989 in the Nepali Himalaya was 2.3 compared to just 1.1 per 100 mountaineers for the period of 1990 to $2006 .{ }^{6}$ This reduction has also been seen on Denali, with a 4\% fall being reported for each year since 1932 and a $53 \%$ reduction following the introduction of new safety measures in $1994 .{ }^{14}$ Nevertheless the mortality rate associated with mountaineering remains high. Not only is it greater than that of other mountain activities, but it is also higher than sports such as hang gliding, parachuting and boxing that are traditionally viewed as dangerous (table 2). ${ }^{16}{ }^{17}$

Although this mortality rate allows comparisons to be made, it does not take into account the impact of different amounts of exposure. To take an extreme example: do professional boxers who fight on a daily or weekly basis for several years have a lower mortality than the mountaineers who undertake a solitary expedition and turn back after a few hours above base camp? In order to acknowledge the impact of the duration of exposure, a different method of calculating mortality rate is required.

Table 2 The mortality rate for specific activities undertaken in the USA that were calculated by dividing the number of deaths by the total number of individuals exposed $^{16-18}$

\begin{tabular}{ll}
\hline Activity & $\begin{array}{l}\text { Mortality rate } \\
\text { (/100 participants) }\end{array}$ \\
\hline Mountaineering & 0.5988 \\
Hang gliding & 0.1786 \\
Parachuting & 0.1754 \\
Boxing & 0.0455 \\
Mountain hiking & 0.0064 \\
Scuba diving & 0.0029 \\
American football & 0.0020 \\
Skiing & 0.0001 \\
\hline
\end{tabular}

The number of deaths for every 1000000 days of exposure to a specific mountain activity

Among skiers and snowboarders, the mortality rate calculated by this method ranges from 0.11 in long distance cross country ski races in Sweden to 2.46 deaths per million exposure days in the downhill ski resorts of Utah, USA. ${ }^{19}{ }^{20}$ The mortality rates of trekkers and mountaineers is greater, with 11 deaths occurring during trekking in Nepal and 1870 deaths per 1000000 exposure days of mountaineering on Mt Cook. ${ }^{12}{ }^{21}$ (table 3).

While the mortality rate of trekkers in Nepal is similar to that found in other activities such as marathon running and motorcycling, the mortality rate of mountaineers is significantly higher. ${ }^{26}$ This is underlined by a recent follow-up study conducted on 46 experienced mountaineers in New Zealand: in just years, four (9\%) had died during mountaineering and seven $(15 \%)$ had retired from the sport. ${ }^{27}$

Despite the widespread use of this calculation, obtaining the mortality rate in this way can be problematic. In small regional studies, information on the number of deaths is usually obtained from local sources. Although these give a highly accurate summary of the deaths that occur within these areas, they can sometimes overlook those who die later following a successful evacuation. Larger studies are also limited, since they often rely upon coroners' reports and assume that the location and activity of the victim before the fatal event is accurately recorded. Calculating the total number of exposure days is also problematic. In studies that calculate skiing and snowboarding mortality, the denominator for the calculation is obtained from either an estimate obtained from a local source such as a park service or from the numbers of admission tickets sold for a given year. These figures tend to ignore those who either work in the region, local residents who possess season tickets, or those who choose to ski off piste and away from designated downhill runs. Despite including the deaths of 100 cross country skiers in their analysis, Xiang et al acknowledged that it was impossible to measure accurately the amount of exposure these individuals had encountered..$^{25}$

Studies that have focused upon trekking and mountaineering have also encountered methodological difficulties. Avery et al used the data from the national census in order to identify the amount of time the population of England and Wales spent mountaineering. ${ }^{8}$ Clearly, this relies upon an individual's own estimate and can therefore be prone to some degree of inaccuracy. Other studies have either used the number of days spent on the mountain or the nights spent in a hut to estimate the amount of exposure. Malcolm, in his study of deaths among mountaineers on Mt Cook, assumed that for every day of mountaineering three nights were spent in one of seven huts on the mountain. ${ }^{21}$ While this may have been a close approximation to the degree of mountaineering exposure, Malcolm focused upon a period of time when the mountaineer was faced with the greatest danger. It was therefore inevitable that the results from $\mathrm{Mt}$ Cook should appear so striking. In contrast, McIntosh et al in their recent study of mortality on Denali included the total amount of time spent on the mountain. ${ }^{14}$ This not only included time spent on the dangerous upper slopes, but also the approach to the mountain from the base camp at $2100 \mathrm{~m}$. Clearly, mortality rates will vary depending upon the locations investigators wish to include. Inevitably this makes comparisons between different studies difficult to make.

Both of the methods described here have significant flaws. However, both can be useful and provide answers to a number of questions. Future studies should consider using both 
Table 3 A summary of those studies that have calculated mortality rate per 1000000 exposure days for specific mountain activities

\begin{tabular}{|c|c|c|c|c|c|c|c|}
\hline Authors & Location & Era & Activity & Deaths & $\begin{array}{l}\text { Age } \\
\text { (years) }\end{array}$ & $\%$ Male & $\begin{array}{l}\text { Mortality rate } \\
\text { (/1 } 000000 \text { exposure } \\
\text { days) }\end{array}$ \\
\hline Avery et al $(1990)^{8}$ & England and Wales & 1982-1988 & Mountaineering & 70 & - & 95 & 2.3 \\
\hline Farahmand et al $(2007)^{19}$ & Vasaloppet, Sweden & $1970-2005$ & Skiing & 13 & 56 & 100 & 0.11 \\
\hline McIntosh et al $(2008)^{14}$ & $\begin{array}{l}\text { Mt McKinley National Park, } \\
\text { USA }\end{array}$ & 1990-2006 & Mountaineering & 96 & 33 & 92 & 100 \\
\hline Morrow $(1988)^{23}$ & Vermont, USA & 1979-1986 & Skiing & 16 & 30 & 81 & 0.67 \\
\hline Shlim and Gallie $(1992)^{13}$ & Nepal & 1984-1987 & Trekking & 23 & - & - & $11 \dagger$ \\
\hline Sherry and Clout $(1988)^{24}$ & Snowy Mountains, Australia & 1956-1987 & Skiing & 29 & 35 & 86 & 0.87 \\
\hline Weston et al $(1977)^{20}$ & Utah, USA & 1969-1974 & Skiing & 10 & 36 & 80 & 2.86 \\
\hline Xiang et al $(2003)^{25}$ & Colorado, USA & 1980-2001 & Skiing and snowboarding & 274 & 32 & 81 & $0.53-1.88^{*}$ \\
\hline
\end{tabular}

*The range of annual mortality rates obtained per 1000000 skier visits to Colorado between 1980 and $2001 .+$ Calculated by Mclntosh et al. ${ }^{14}$

approaches in order to provide the most comprehensive analysis.

\section{MECHANISMS OF MOUNTAIN MORTALITY}

While no single method of measuring mortality rate is ideal, it is clear that a considerable number of deaths occur in mountain regions. How do they die?

\section{Trauma}

It is perhaps not surprising to learn that skiers, snowboarders, trekkers and mountaineers die in different ways. Fatalities in downhill skiing and ski jumping tend to occur as a result of a fall or a collision with either a tree, post or other skiers (table 4). ${ }^{19} 2022-2528$

In these cases deaths tend to be due to multiple blunt trauma to the head, chest and abdomen. ${ }^{29}{ }^{30}$ Deaths among trekkers and mountaineers are largely due to falls and tend to result in a similar pattern of injury. ${ }^{12-15}{ }^{31}$ In a study of mountaineering and rock climbing injuries in the USA, Addiss and colleagues were able to demonstrate that the median distance of a fatal fall was $91 \mathrm{~m}$ compared to a non-fatal fall of just $9 \mathrm{~m}(\mathrm{p}<0.001)$. The risk of death was influenced by the angle of the slope, the landing surface and the efforts made by the victim and climbing partner to arrest the fall. ${ }^{32}$

The pattern of deaths among mountaineers is also related to the time spent in certain areas. Sherpa mountaineers working on the Nepali side of Mt Everest spend considerable amounts of time carrying equipment through the dangerous Khumbu Icefall and other avalanche prone areas in the Western Cwm. This leads to a considerable number of deaths caused by falling snow, ice and rock on lower sections of the route. ${ }^{11}$

Cross country skiers and mountaineers are at a much greater risk from the dangers of rockfall, icefall and avalanches than those who prefer to stay within the confines of conventional ski runs. Between 1994 and 2003, the median annual mortality from snow avalanches in Europe and North America was $141 .^{33}$ The majority of these victims died from asphyxia rather than the result of traumatic injuries that had occurred during snow burial. $^{34}$ In a recent analysis of 36 avalanche fatalities, a team from the University of Innsbruck identified a traumatic cause of death in only two victims (5.6\%). The remainder were found to have died from either hypothermia (2.8\%) or asphyxia (91.6\%). ${ }^{34}$ Following a complete snow burial, death from asphyxia is rapid with approximately $60 \%$ of those buried in an avalanche dying within 15-35 $\min ^{35}$

\section{Cold injury}

Since ambient temperature falls by approximately $5.5^{\circ} \mathrm{C}$ for every $1000 \mathrm{~m}$ of altitude, it is inevitable that the cold will contribute to a number of deaths in the mountains. ${ }^{2}$ Deaths caused by hypothermia tend to occur as a result of an unexpected event such as a musculoskeletal injury or an episode

Table 4 Summary of the causes of death found in studies of skiers and snowboarders

\begin{tabular}{|c|c|c|c|c|c|c|c|c|}
\hline Author & Location & Activity & Deaths & Collision & Fall & Avalanche & Hypothermia & Medical \\
\hline Farahmand et al $(2007)^{19}$ & Vasaloppet, Sweden & Cross country skiing & 13 & 0 & 0 & 0 & 0 & 13 \\
\hline Morrow $(1988)^{23}$ & Vermont, USA & Skiing & 16 & 6 & 10 & 0 & 0 & 0 \\
\hline Sherry and Clout $(1988)^{24}$ & $\begin{array}{l}\text { Snowy Mountains, } \\
\text { Australia }\end{array}$ & Skiing & 29 & 4 & 3 & 1 & 6 & 15 \\
\hline Tough and Butt ${ }^{*}(1993)^{29}$ & Alberta, Canada & Cross country skiing & 19 & 1 & 2 & 15 & 1 & 0 \\
\hline Tough and Butt ${ }^{*}(1993)^{30}$ & Alberta, Canada & Skiing & 19 & 12 & 6 & 0 & 1 & 0 \\
\hline Weston et al $(1977)^{20}$ & Utah, USA & Skiing & $10 \dagger$ & 2 & 3 & 1 & 0 & 3 \\
\hline Xiang et al $(2003)^{25}$ & Colorado, USA & Cross country skiing & $100 \%$ & 5 & 2 & 84 & NK & 4 \\
\hline Total & & & 386 & 145 & 41 & 109 & 8 & 42 \\
\hline
\end{tabular}

*Only deaths associated with traumatic injuries or hypothermia were included. †One death was attributed to suicide following a single gunshot wound to the head. $¥$ Xiang et al's study was divided into deaths that occurred to either downhill skiing and snowboarding or cross country skiing. The remaining deaths in this study were attributed to either "general skiing accidents" or "other/unknown".

NK, not known. 


\section{Key learning points}

- Obtaining a meaningful and accurate picture of mortality in the mountains is not a straightforward task.

- In mountain activities the mortality rate is calculated in two ways: the number of deaths divided by the total number of individuals exposed, or as the number of deaths for every 1000000 days of exposure to a specific mountain activity.

- The reported mortality rate among skiers and snowboarders is 0.11 and 2.46 deaths for every million days of exposure, while the mortality rate among mountaineers is 2.3 to 1870 deaths for every million days of exposure.

- Deaths in the mountains are most commonly due to trauma, high altitude illness, cold injury, avalanche burial, and sudden cardiac death.

of high altitude illness. ${ }^{14} 29$ Alternatively, environmental factors such as an avalanche burial or deteriorating weather conditions can also be responsible..$^{15}$ In some cases equipment failure has also been blamed. Damage to skis and their bindings can leave cross country skiers stranded in remote areas, while loss of crampons or ice axes can slow a mountaineer's descent and increase the time spent exposed to the cold.

\section{High altitude illness}

An ascent to altitude results in a fall in barometric pressure and a subsequent reduction in the partial pressure of inspired oxygen. In order to cope with this change the human body undergoes a process of acclimatisation. In those who ascend rapidly, this can be incomplete and result in the development of life threatening conditions such as high altitude pulmonary oedema (HAPE) and high altitude cerebral oedema (HACE). In a study of Indian soldiers, $5.7 \%$ of those who were flown to altitudes of $3500 \mathrm{~m}$ contracted HAPE compared to just $0.3 \%$ who completed the same journey by road. ${ }^{36}$ The incidence of these conditions also increases with altitude. On arrival at $3063 \mathrm{~m}, 0.1 \%$ of lowland residents had evidence of HAPE compared to $5.3 \%$ at $4486 \mathrm{~m} .{ }^{37}$ In a number of cases, HAPE and HACE coexist. Up to $20 \%$ of those who present with HAPE also demonstrate signs of HACE, while up to $50 \%$ of those who died from HAPE also had evidence of HACE on autopsy. ${ }^{38} 39$ Historically, HAPE and HACE have been thought to be responsible for the majority of deaths that occur at altitude. While evidence collected in this review would suggest that this is not the case, it is possible that HAPE and HACE contribute in some part to those deaths attributed to trauma or hypothermia. In the early stages of HACE, changes in consciousness, abnormalities in motor function and the presence of visual disturbances can occur, while in HAPE, lethargy, malaise and breathlessness are commonly seen. ${ }^{11}$ Clearly these symptoms can have an adverse effect on anyone undertaking physical activities at altitude and have the potential to increase the risk of a fatal fall or prolong a period of cold exposure that subsequently results in hypothermia.

\section{Sudden cardiac death}

While HAPE and HACE tend to figure highly among nontraumatic deaths on the highest peaks, at lower altitudes sudden cardiac death $(\mathrm{SCD})$ appears to be more prevalent. ${ }^{24} 40$ SCD is defined as an "unexpected, non-traumatic death that occurs within one hour of the onset of symptoms", and accounts for up to $52 \%$ of deaths during downhill skiing and

\section{Current research questions}

- How do differences in activities and environmental factors impact upon mortality rates in the mountain environment?

- How can deaths from trauma, cold injury, high altitude illness and sudden cardiac death be reduced in the mountain environment?

$30 \%$ of mountain hiking fatalities. ${ }^{24}{ }^{40}$ The reported incidence of SCD in mountain regions ranges from approximately 1 to $10^{\mathrm{i}}$ per million person days activity in the mountains. ${ }^{40}{ }^{41}$ In adults, vigorous exercise, such as that seen in mountain activities, is associated with an increase in the incidence of SCD. ${ }^{42}$ Vigorous physical exertion has been reported to have occurred within $1 \mathrm{~h}$ of myocardial infarction in $4-10 \%$ of cases. ${ }^{43}$ Studies of long distance skiers and runners demonstrate that the incidence of SCD in adults is between 5-50 times greater during exercise than during sedentary activities. ${ }^{44-46}$ In most cases SCD is due to coronary artery disease and is reflected by the sex and age distribution of those who die from the condition. ${ }^{47}$ In studies undertaken in the European Alps between $90-95 \%$ of SCDs occurred in males, while the frequency of SCD has been shown to increase dramatically in those aged over 34 years. ${ }^{40} 41$ Importantly, only those who undertake regular exercise are afforded significant protection from the risk of SCD during vigorous activity. The relative risk of a life threatening cardiac event has been shown to be 150 in sedentary individuals and just 5 in those individuals who undertake regular exercise. ${ }^{48}$ Among the 38 SCDs identified in the Tyrolean Alps between 1999 and 2002, 86\% did not take regular physical activity. ${ }^{41}$

Rigorous exercise has a profound effect upon the autonomic nervous system, prompting changes in myocardial electrical stability and increases in an individual's susceptibility to fatal arrhythmias. ${ }^{49}$ Fortunately, regular exercise not only increases basal vagal tone and enhances electrical stability, but also prevents the development of coronary artery disease and the formation of vulnerable plaques that are prone to rupture during surges in sympathetic activity. ${ }^{42} 5051$ Unfortunately, many heading to the mountains are sedentary and prone to coronary artery disease. In a study of hikers and skiers in the Tyrolean Alps, up to $21.7 \%$ undertook less than $1 \mathrm{~h}$ of exercise per week and $12.7 \%$ had a history of cardiovascular disease..$^{52}$ It therefore seems inevitable that a significant number of SCDs will occur in the mountains.

\section{CONCLUSION}

Although only a small number of deaths occur in the mountain environment, their unexpected nature raises a considerable amount of concern in wider society. In order to devise strategies to prevent these deaths, it is important that mortality rates can be calculated. However, differences in the activities, environmental conditions and methods of calculation often make these results difficult to interpret. Nevertheless, a number of conclusions can be drawn. Firstly, the mortality rate among skiers and snowboarders occupies a narrow range: between 0.11-2.46 deaths for every million days of exposure. Secondly, the mortality rate for mountaineering is greater and varies enormously: 2.3 to 1870 deaths for every million days of

i This was calculated from Burtscher et al's results that showed one SCD for every 780000 hiking hours. ${ }^{40}$ It assumed that $8 \mathrm{~h}$ of hiking was equivalent to 1 day of activity in the mountains. 


\section{Key references}

- Firth PG, Zheng H, Windsor JS, et al. Mortality on Mt Everest 1921-2006: descriptive study. BMJ 2008;337:a2654.

- McIntosh SE, Campbell AD, Dow J, et al. Mountaineering fatalities on Denali. High Alt Med Biol 2008;9:89-95.

- Christensen ED, Lacsina EQ. Mountaineering fatalities on Mt Rainier, Washington, 1977-1997: autopsy and investigative findings. Am J Foren Med Path 1999;20:173-9.

- Hackett PH, Roach RC. High altitude cerebral edema. High Alt Med Biol 2004;5:136-46.

- Burtscher M, Philadelphy M, Likar R. Sudden cardiac death during mountain hiking and downhill skiing. $N$ Engl J Med 1993;329:1738-9.

exposure. Finally, the difference between the two groups may be explained by not only the activity itself but also by the environment each activity operates in. The ski resort is likely to be a far safer place than the remote mountain cliff!

Fortunately, there is now evidence demonstrating that in recent years mortality rates have begun to fall. Nevertheless, the mountain remains a dangerous place and care must be taken by anyone who straps on skis or crampons and ventures into them.

\section{MULTIPLE CHOICE QUESTIONS (TRUE (T)/FALSE (F); ANSWERS AFTER THE REFERENCES)}

\section{Mountain regions:}

A. Occupy 40 million $\mathrm{km}^{2}$

B. Account for $2.7 \%$ of the earth's surface

C. Attract 100 million visitors for work and recreation each year

D. Above 8000 feet $(2667 \mathrm{~m})$ are home to 0.38 million people

E. In Nepal have seen the numbers of visitors fall over the last two decades

\section{The mortality rate calculated by dividing the number of deaths by the total number of individuals exposed:}

A. Has increased among US mountaineers over the last 50 years

B. Is higher in swimmers than mountaineers

C. Has been falling on Denali

D. Ranges from 10 to 12.6 deaths for every 100 mountaineers climbing above $6000 \mathrm{~m}$ in the Himalayas

E. Is $13 \%$ on Mt Everest

\section{In the mountains:}

A. Deaths caused by avalanches are normally due to trauma

B. Deaths among sherpas on Mt Everest tend to occur low on the mountain

C. Cross country skiers and mountaineers are at a much greater risk from the dangers of rockfall, icefall and avalanches than those who prefer to stay within the confines of conventional ski runs

D. Ambient temperature falls by approximately $0.5^{\circ} \mathrm{C}$ for every $1000 \mathrm{~m}$ of altitude

E. $60 \%$ of those buried in an avalanche die within $15-35 \mathrm{~min}$

\section{High altitude illnesses:}

A. Are the result of a fall in the partial pressure of inspired oxygen

B. Are responsible for the majority of non-traumatic deaths in the mountains

C. Are more common following a slow ascent

D. Rarely coincide

E. May contribute to other mechanisms of death

\section{Sudden cardiac death:}

A. Has been defined as an "unexpected, non-traumatic death that occurs within $24 \mathrm{~h}$ of the onset of symptoms"

B. Has been shown to account for up to $52 \%$ of deaths during downhill skiing and $30 \%$ of mountain hiking fatalities

C. Is due to coronary artery disease in the majority of cases

D. Risk is reduced in those who exercise regularly

E. In the mountain environment increases dramatically in men aged over 34 years

Competing interests: None.

\section{REFERENCES}

1. Mallory GL. The reconnaissance of the mountain. In: Howard-Bury CK, ed. Mt Everest: the reconnaissance. London: Edward Arnold, 1921:214-5.

2. World Health Organisation. Introduction to mountain regions. http://www.searo. who.int/LinkFiles/Publications_and_Documents_healthlmapctsC2.pdf (Accessed 1 Nov 2008).

3. Moore LG. Altitude-aggravated illness: examples from pregnancy and prenatal life. Ann Emerg Med 1987; 16:965-73.

4. Burtscher M, Bachmann 0, Hatzl T, et al. Cardiopulmonary and metabolic responses in healthy elderly humans during a 1-week hiking programme at high altitude. Eur J Appl Physiol 2001;84:379-86

5. Gaillard S, Dellasanta P, Loutan P, et al. Awareness, prevalence, medication use and risk factors of acute mountain sickness in tourists trekking around the Annapurnas in Nepal: a 12 year follow up. High Alt Med Biol 2004;5:410-9.

6. Salisbury R, Hawley E. The Himalaya by the numbers. 2007. www. himalayandatabase.com (Accessed 1 June 2008)

7. Ward MP, Milledge JS, West JB. High altitude medicine and physiology, 3rd ed. London: Arnold, 2000:22-44.

8. Avery JG, Harper P, Ackroyd S. Do we pay too dearly for our sport and leisure activities? An investigation into fatalities as a result of sporting and leisure activities in England and Wales, 1982-1988. Public Health 1990;104:417-23.

9. Williamson JE, Podemski E, eds. Accidents in North American mountaineering. American Golden, Colorado: Alpine Club, 2007:69-70 (table 1).

10. Pollard AJ, Clarke C. Deaths during mountaineering at extreme altitude. Lancet 1988;1:1277.

11. Firth PG, Zheng H, Windsor JS, et al. Mortality on Mt Everest 1921-2006 descriptive study. BMJ 2008;337:a2654.

12. Schlim DR, Houston R. Helicopter rescues and deaths among trekkers in Nepal. JAMA 1989:261:1017-9.

13. Shlim DR, Gallie J. The causes of death among trekkers in Nepal. Int J Sports Med 1992;13:S74-6.

14. McIntosh SE, Campbell AD, Dow J, et al. Mountaineering fatalities on Denali. High Alt Med Biol 2008;9:89-95.

15. Christensen ED, Lacsina EQ. Mountaineering fatalities on Mt Rainier, Washington, 1977-1997: autopsy and investigative findings. Am J Foren Med Path 1999;20:173-9.

16. Wright JR. Nordic ski jumping fatalities in the United States: a 50 year summary. J Trauma 1988:28:848-51.

17. Reif AE. Risks and gains. In: Vinger PF, Hoerner EF, eds. Sports injuries. The unthwarted epidemic, 2nd ed. Littleton: MA PSG Publishing Co, 1986:48-57.

18. Hart AJ, White SA, Conboy PJ, et al. Open water scuba diving accidents at Leicester: five years experience. J Accid Emerg Med 1999;16:198-200.

19. Farahmand B, Hallmarker U, Brobert GP, et al. Acute mortality during long distance ski races (vasaloppet). Scand J Med Sci Sports 2007;17:356-61.

20. Weston JT, Moore SM, Rich TH. A five year study of mortality in a busy ski population. J Forens Sci 1977;22:222-30.

21. Malcolm M. Mountaineering fatalities in Mt Cook National Park. NZ Med J 2001:114:78-80.

22. Corra S, Conci A, Conforti G, et al. Skiing and snowboarding injuries and their impact on the emergency care system in South Tyrol: a retrospective analysis for the winter season 2001-2002. Inj Con Saf Prom 2004;11:281-5.

23. Morrow PL, McQuillen EN, Eaton LA, et al. Downhill ski fatalities: the Vermont experience. J Trauma 1988;28:95-100.

24. Sherry E, Clout L. Deaths associated with skiing in Australia: a 32 year study of cases from the Snowy Mountains. Med J Aust 1988;149:615-8. 
25. Xiang H, Stallones L. Deaths associated with snow skiing in Colorado 1980-1981 to 2000-2001 ski seasons. Injury 2003;34:892-6.

26. Tunstall-Pedoe DS. Sudden death risk in older athletes: increasing the denominator. Br J Sports Med 2004;38:671-2.

27. Montasterio ME. Accident and fatality characteristics in a population of mountain climbers in New Zealand. NZ Med J 2005;118:U1249.

28. Wright JR. Nordic ski jumping fatalities in the United States: a 50-year summary J Trauma 1988;28:848-51.

29. Tough SC, Butt JC. A review of 19 fatal injuries associated with backcountry skiing. Am J Forensic Med Path 1993;14:17-21.

30. Tough SC, Butt JC. A review of fatal injuries associated with downhill skiing Am J Forensic Med Path 1993;14:12-6.

31. Reid WA, Doyle D, Richmond HG, et al. Necropsy study of mountaineering accidents in Scotland. J Clin Pathol 1986;39:1217-20.

32. Addiss DG, Baker SP. Mountaineering and rock climbing injuries in US national parks. Ann Emerg Med 1989;18:975-9.

33. Brugger $\mathbf{H}$, Etter HJ, Zweifel B, et al. The impact of avalanche devices on survival. Resuscitation 2007;75:476-83.

34. Hohlrieder M, Brugger $\mathrm{H}$, Schubert HM, et al. Pattern and severity of injury in avalanche victims. High Alt Med Biol 2007;8:56-61.

35. Falk M, Brugger $\mathrm{H}$, Adler-Kastner L. Avalanche survival chances. Nature 1994;368:21.

36. Purkayastha SS, Ray US, Arora BS, et al. Acclimatization at high altitude in gradual and acute induction. J Appl Physiol 1995;79:487-92.

37. Hultgren H. High altitude medicine. Stamford: Hultgren Publications, 2001.

38. Gabry AL, Ledoux X, Mozziconacci M, et al. High altitude pulmonary edema at moderate altitude ( $<2400 \mathrm{~m} ; 7870$ feet): a series of 52 patients. Chest 2003:123:49-53.

39. Hackett PH, Roach RC. High altitude cerebral edema. High Alt Med Biol 2004:5:136-46

40. Burtscher M, Philadelphy M, Likar R. Sudden cardiac death during mountain hiking and downhill skiing. N Engl J Med 1993;329:1738-9.

41. Ponchia A, Biasin R, Tempesta T, et al. Cardiovascular risk during physical activity in the mountains. J Cardiovasc Med 2006;7:129-35.
42. Willich SN, Lewis M, Lowel $\mathrm{H}$, et al. Physical exertion as a trigger of acute myocardial infarction. Triggers and mechanisms of myocardial infarction study group. N Engl J Med 1993;329:1684-90.

43. Mittleman MA, Maclure M, Tofler GH, et al. Triggering of acute myocardial infarction by heavy physical exertion. Protection against triggering by regular exertion. Determinants of myocardial infarction onset study investigators. N Engl J Med 1993;329:1677-83

44. Marti B, Goerre S, Spuhler T, et al. Sudden death during mass running events in Switzerland 1978-1987: an epidemiologico-pathologic study. Schweiz Med Wochenschr 1989:119:473-82

45. Siscovick DS, Weiss NS, Fletcher RH, et al. The incidence of primary cardiac arrest during vigorous exercise. N Engl J Med 1984;311:874-7.

46. Thompson PD, Funk EJ, Carleton RA, et al. Incidence of death during jogging in Rhode Island from 1975 through 1980. JAMA 1982;247:2535-8.

47. Vuori I. The cardiovascular risks of physical activity. Acta Medica Scand 1986;711:205-14.

48. Bartels $\mathbf{R}$, Menges $\mathrm{M}$, Thimme $\mathrm{W}$, et al. Effect of physical activity on incidence of sudden cardiac death. Study of the Berlin-Reinickendorf and Berlin-Spandau population. Med Klin (Munich) 1997:92:319-25

49. Peronnet $\mathbf{F}$, Cleroux $\mathrm{J}$, Perrault $\mathrm{H}$, et al. Plasma norepinephrine response to exercise before and after training in humans. J Appl Physiol 1981:51:812-5

50. Hull SS, Vanoli E, Adamson PB, et al. Exercise training confers anticipatory protection from sudden death during acute myocardial ischaemia. Circulation 1994;89:548-52.

51. Burke AP, Farb A, Malcolm GT, et al. Plaque rupture and sudden death related to exertion in men with coronary artery disease. JAMA 1999;281:921-6.

52. Faulhaber M, Flatz M, Gatterer $\mathrm{H}$, et al. Prevalence of cardiovascular diseases among alpine skiers and hikers in the Austrian Alps. High Alt Med Biol 2007;8:245-52.

Answers
$\begin{array}{ll}\text { 1. A (T); B (F); C (T); D (F); E (F) } \\ \text { 2. } \quad \text { A (F); B (F); C (T); D (F); E (F) } \\ \text { 3. } & \text { A (F); B (T); C (T); D (F); E (T) } \\ \text { 4. } & \text { A (T); B (F); C (F); D (F); E (T) } \\ \text { 5. } & \text { A (F); B (T); C (T); D (T); E (T) }\end{array}$

